\title{
Liver metastasis in a case of adenoid cystic carcinoma of the Bartholin's gland: a rare presentation
}

\author{
Shohreh Shahabi $\cdot$ Lisa M. Nathan · Charu Chanana • \\ Wendy S. Garrett $\cdot$ Wenxin Zheng • \\ Thomas J. Rutherford
}

Published online: 9 November 2008

(C) Springer-Verlag 2008

\section{Erratum to: Arch Gynecol Obstet}

DOI 10.1007/s00404-008-0771-8

Unfortunately, the online version of this article does not have addresses of the authors. The addresses are given below.

The online version of the original article can be found under doi:10.1007/s00404-008-0771-8.

\section{S. Shahabi $(\bowtie) \cdot$ L. M. Nathan}

Division of Gynecologic Oncology,

Department of Obstetrics and Gynecology

and Women's Health, Albert Einstein College of Medicine

and Montefiore Medical Center, Bronx, NY 10461, USA

e-mail: sshahabi@montefiore.org

C. Chanana

Department of Obstetrics and Gynecology,

Bronx Lebonan Hospital, New York, USA

W. S. Garrett

Department of Medical Oncology,

Dana Farber Cancer Institute, Boston, MA 02115, USA

\section{W. Zheng}

Department of Pathology, Arizona Cancer Center,

University of Arizona College of Medicine,

Tucson, AZ 85724, USA

T. J. Rutherford

Division of Gynecologic Oncology,

Department of Obstetrics, Gynecology and Reproductive

Medicine, Yale University School of Medicine,

333 Cedar Street, New Haven, CT 06510, USA 